\title{
Overview of measures taken in the area of health care reforms in Croatia and their results
}

\begin{abstract}
This article examines the series of reforms which have made in the health care sector over the last two decades in Croatia, a country with a strong public health care tradition, towards an increasing commercialisation of health services. After describing the three major reform packages (in 1993, 2000 and 2006), some of which have been made under the influence of the international financial institutions, and the current structure of the Croatian health care system, the article details the critical views of Croatia's major trade unions to the current five-year National Strategy for health care. The article focuses on the debate which is taking place surrounding the reduction in public expenditure on health care and the increasing reliance on private resources, and the likely effects of this switch in driving a division in health care based on the ability to pay for it.
\end{abstract}

Keywords: Croatia, health care reform, international financial institutions, national strategy, public expenditure, co-financing of health care, additional and supplementary health insurance, health care employees, trade unions.

\section{Introduction}

The universal right to health care in Croatia is enshrined in the Constitution of the Republic of Croatia and is guaranteed to all its citizens.

Making up a part of public policy, health policy is of great social importance and a subject of much public discussion. This is so not only because health care systems require considerable funds but also because the right to health is related to the rights guaranteed under the Constitution and mistakes within the system can have serious social consequences.

The health care system and its structure fall within the general public interest; however, health policy is not considered sufficiently transparently but is shaped within the closed political circles guided by the policy of the international financial institutions, i.e. the International Monetary Fund and the World Bank. There is a pressure on the part of the international financial institutions to transform the traditionally European system of a socially-regulated market and social cohesion, and to 'adjust' it to the new globalised reality or else to replace it with a new model, with transition countries, such as Croatia, offering an ideal opportunity for such a policy. The result is globally known: profit rates are increasing while the income of the population is decreasing. The solution is evident: reduce the funds for social items (including health) and thus reduce the responsibility of the state.

The Croatian health care system has undergone significant changes and has been in a state of 'permanent' transition for almost two decades. Despite a number of reforms, the Croatian health system still faces many problems. Most reforms have dealt 
with restricting the rise in costs, resulting in a 'transfer' of part of those costs to citizens and ensuring the right to health only to those who could afford it.

Furthermore, it is clear that the citizens of Croatia are not satisfied with the current health care situation. One of the most obvious examples of the failure on the part of the state in the health sector is the fact that corruption is widespread. According to a survey conducted by Transparency International (2005), 32\% of Croatian citizens believe that corruption in health care is 'spread' and $48 \%$ that it is 'quite spread'. Similarly, as many believe, the health sector is the point of the greatest inequality between citizens.

This article will analyse the measures undertaken within health care reforms and their influence on the current health care system in Croatia.

\section{Health reforms in Croatia}

After the 1990s, there has been a number of health care system reforms in Croatia. In the following text, we mention only some of the changes in the health policy and health system resulting from these reforms.

\section{The 1993 health reform}

The first extensive health reform was carried out in 1993. It was characterised by a centralisation of funding and by a so-called 'health system privatisation' relating to primary health care, which was governed by secondary legislation. This undermined the famous 'Štampar model' of health care of the population. The 1993 Law on Health Care defined the universal 'coverage' of citizens by health insurance, universal access to health care and the right to a free choice of medical doctors and dentists, and introduced a mixed public and private system of health care services. Furthermore, social ownership of the health care institutions was replaced with state ownership, ownership by local self-governing units and private ownership.

Counties provided funds for the construction, equipment and establishment of health care institutions at the level of primary and secondary health care. Doctors were given the right to offer primary health care services under a contract with the Croatian Institute for Health Insurance.

The 2000 health reform

2000 saw rather ambitious health reform measures introduced under the influence of the World Bank. They had three main goals:

a. solving the financial issues of the health care system (at that point, the share of health costs in GDP was $9 \%$ )

b. making changes to health system management and improving its efficiency and quality

c. strengthening primary and preventive health care.

The reform aimed at achieving the financial sustainability of the system through a reduction of the rights included in basic health insurance, the introduction of participation fees and the encouragement of additional health insurance which provided for the difference in the values of health services within basic health insurance which were not covered by the Croatian Institute for Health Insurance. The number of citizens not obliged to pay participation fees was reduced. This category included children under 18 , pensioners, pregnant women and mothers on maternity leave, unemployed people, etc, and accounted for 1.7 to 2 million people out of the 4.5 million 
citizens of Croatia. In the first two years, the legislator transferred additional health insurance to the Croatian Institute for Health Insurance alone (not to other private insurers).

The law restricted the right of primary health care doctors to determine the duration of sick leave, while the lowest level of sick leave reimbursement was reduced from $80 \%$ to $70 \%$ of the reimbursement basis (the insured person's average wage in the six months before the occurrence of the grounds entitling them to reimbursement). County health centres were established, as were their local outpatient facilities.

Both cities and counties raised additional funds by ceding an additional share in income tax for the investment maintenance of the health care institutions owned by the counties. These reforms launched the decentralisation of the health care system.

The Croatian Institute for Health Insurance lost its financial independence as it became part of the central state budget.

The fact that these reforms did not lead to the expected financial economies in the health system created a need for a fresh round of reforms in 2006.

\section{The 2006 health reform}

The latest reform began in 2006, with the aim of introducing a new structure into the health system due to its inefficiency, lack of transparency and lack of structural harmonisation. The reform focused on controlling the rise in costs, in particular of those for medicines. The key document from this period was the National Strategy for Health Care Development 2006-2011, adopted by the Croatian parliament in June 2006. In addition to the Strategy, parliament also adopted a set of laws for implementing the tasks defined by the Strategy:

- Compulsory Health Insurance Act

- Voluntary Health Insurance Act

- amendments to the Health Care Act

- Health Insurance for On-Duty Injuries and Occupational Illnesses Act.

At the time, the health system faced problems arising from the territorial lack of harmonisation of secondary health care capacities; a concentration of specialist and advisory services within tertiary health care institutions which, in turn, were too concentrated in the capital; a lack of hospital categorisation; the further reduction of the role of primary health care and the further reduction in the number of preventive check-ups; etc. Similarly, it was established that Croatia allocated a relatively large share of GDP to health care, as well as that the expenditure structure was inadequate as Croatia spent too much public money and not enough private money. Increasing the share of private expenditure within the health system was one of the measures aiming at reducing public expenditure in the health system.

The Strategy provided detailed explanations of measures for promoting the territorial, temporal and economic accessibility of health services, as well as their fairness and equality; health care efficiency; improving the quality of medical work and the safety of patients and health professionals; and solidarity. One of the key principles was the establishment of integrated health protection, which included the strengthening of primary health care as the key element of integrated health care, efficient monitoring of the use of secondary and tertiary capacities and general expenditure in the health sector, and resolving up to $80 \%$ of medical cases at the level of primary health care. 
The health costs indicator was precisely the indicator which had been defined as one of the key reasons for carrying out health reform, as well as the health condition of the population and, generally, the efficiency of the health system under relevant international standards. The strategic approach of the government was to reduce the share of health in GDP from $9 \%$ to $6 \%$ by 2011 , implying a decrease in public resources for health funding.

Thus, we got a 'reform' in accordance with the goals defined in the Programmatic Adjustment Loan (PAL) of the World Bank:

- reducing expenditure relating to medicines

- reducing hospital deficits

- changing the basic health insurance package

- restructuring the expenditure of social contributions.

The proposed health reform, as defined in the Strategy, met severe opposition on the part of certain trade union centres. These trade union centres stated that the National Health Strategy 'suffered' from it not being a strategy but an (incomplete) overview of the current problems as well as a 'list' of steps to be taken in 'the following period'. It lacked clearly-defined strategic goals, measures, time frames, implementers and criteria for monitoring and evaluating the foreseen measures. Furthermore, the trade unions pointed out that the five-year time frame of the Strategy (2006-2011) suggested that the Croatian government did not have a clear vision for the medium- and long-term health system in Croatia, or even what the medium- and long-term goals of health policy in Croatia were. In other words, it was not evident what the Strategy aimed to achieve and improve. It also lacked a financial plan for the implementation of the Strategy, as well as the locus of the responsibility for any failure to achieve its goals or implement its measures. The trade unions thought that the proposed Strategy and the proposed 'package' of laws aimed primarily at reducing the rights of insured persons and 'saving' money (at their own expense). Trade unions also saw the 'package' of laws as a means to maintain the status quo within the health system, with a far less favourable status for the beneficiaries of health care. The trade unions requested that, before the laws were passed, the situations and relationships within the system be resolved (i.e. standard operation procedures introduced, IT established in the system, a plan adopted for the efficient use of existing health resources, the categorisation and accreditation of hospitals carried out, etc.); however, this request was not supported.

Moreover, trade unions strongly opposed the 'strategic approach' of reducing the share of public expenditure allocated to health care at the expense of private resources, considering that, at the time, Croatia had 314000 unemployed persons while $18.8 \%$ of the Croatian population faced the risk of poverty. The average amounted to 4500 kuna, while the average pension in 2005 was 1244 kuna.

In response to the announced health reform, the four trade union centres in Croatia - i.e. the Association of Independent Trade Unions, Independent Trade Unions of Croatia, Croatian Trade Union Association and UNI-CRO Services Trade Union - organised a petition for health and pensions reform in companies and city squares from 1 to 21 of March 2006. This activity resulted in the signatures of over 330000 Croatian citizens who thus expressed their dissatisfaction with the situation of the health care system. 
The above Strategy and related laws have re-introduced certain novelties into the health care system - which are in force even today and which define the current health care system in Croatia.

\section{Health care system in Croatia today}

Health care system structure

During the 1980s, the health care system in Croatia was quite decentralised and marked by a high degree of autonomy of local authorities as well as by the participation of both health care professionals and beneficiaries in decision-making. At the time, health care organisations were poorly organised, without proper management, and were considerably inefficient.

During the 1990s, the health care system saw radical reforms; within the context of the entire system of public services, the reforms also encompassed the health care system.

One of the measures at the time was the centralisation of the health funding system, justified by the lack of co-operation and monitoring relating not only to public services in general but also to each individual health system. Such changes were introduced within the 1993 reform which, despite having introduced certain elements of decentralisation (e.g. health care institutions being owned by local authorities and the privatisation of primary health care), ensured quite strong central control over the funding and financial management of the health care system.

Unlike the situation at the beginning of the transition, the current health care system is more centralised. In addition to the public sector, the private sector is increasingly offering its services. Despite positive changes, the health care system in Croatia is still facing major problems; reforms proceed, problems remain.

After the centralisation of the beginning of the 1990s, management decentralisation has put most health care institutions under the supervision of local selfgovernance units which, however, lacked sufficient funds, as well as management and monitoring capacities, to ensure the efficient operation of hospitals.

In the last few years, reforms have focused on different aspects of health funding. There have been efforts to slow down the growth in expenditure from public sources and to transfer the growing burden to citizens.

The organisation of the health system was mostly outlined in the previous descriptions of the reforms, but a brief summary will be given here.

Under the Health Care Act and its 2006 amendments (Official Gazette Nos. 121/ $03,48 / 05,85 / 06)$, health care is defined as a system of social, collective and individual measures, services and activities for preserving and promoting health and preventing diseases; the early detection of disease; timely treatment and health care; and rehabilitation. It has three main levels:

- primary

- secondary

- tertiary

- the level of health institutes.

The primary level is responsible for: monitoring the health condition of the population and proposing measures for the protection and promotion of citizens' health; the prevention and detection of disease; the treatment and rehabilitation of people 
who are ill; specific preventive health protection for children and young people, and of women; preventive health protection for at-risk groups and other citizens in accordance with preventive health care programmes; counselling; health education and the promotion of its protection; protection in terms of hygiene and epidemiology; prevention, detection and treatment of oral diseases with rehabilitation; health rehabilitation of children and young people with difficulties in their physical and mental development; domiciliary care; health visits and treatment; occupational medicine; emergency care; palliative care; and mental health protection.

Primary-level institutions include community health centres, emergency care institutions, medical care institutions, pharmacies and palliative care institutions.

All these institutions are owned by the counties although there are, for example, a number of doctors working within community health centres who, due to the privatisation process, have leased their practices.

Secondary-level health care includes specialist and advisory services and hospital services. Secondary-level institutions include polyclinics, hospitals and sanatoria; they are also owned by the counties.

Tertiary-level institutions (clinical hospitals) are owned by the state and offer the most complex forms of health care pertaining to specialist and advisory services and hospital services; they are also engaged in teaching and research.

Health institutes form part of the health care services provided at the primary, secondary and tertiary levels. In these terms, the level of state health institutes refers to public health services, occupational medicine, transfusion medicine and mental health protection while the level of regional local self-governance health institutes refers to public health services.

One of the main problems arising from the structure of the health system is an imbalance between primary and secondary health protection. In most European countries, primary health care institutions deal with approximately $75 \%$ of medical cases whereas, in Croatia, primary health care resolves only $50 \%$ of such cases. In addition, the number of patients treated in secondary and tertiary health care institutions, where the costs are much higher, has increased by $30 \%$ in the past five years. This has resulted in the wasteful duplication of a number of diagnostic and laboratory procedures, as well as in a significant increase in the costs of health care. On the other hand, hospitals have faced both a lack of funds and service quality assessment systems (WHO, 2005).

Management rights within the health system are divided in accordance with related ownership, i.e. between the state and the counties which have a certain role in health service management. The government defines a framework plan and policy within which the counties pursue their own health policies. In addition, certain planning roles and management and supervisory tasks are given over to the counties. In practice, management is transferred to institutions offering health care services, such as health care institutions and hospitals, which are managed by relevant management bodies. All health care institutions are managed by institution managers and deputy managers, one of which must be a doctor with no less than five years of hospital experience. Each health care institution has its management board composed of representatives of the owner and of employees. 


\section{Health care system funding}

It has already been mentioned that the main goal of the latest reforms within the health care system has been to reduce public expenditure in public health funding and to transfer the relevant costs to citizens. The strategy mentions the following as the basis of the health care funding policy, subsequently articulated in legal provisions:

- reducing the share of public expenditure in health care to the account of private expenditure; regulating additional and supplemental health insurance

- defining a negative basic health insurance package (procedures not covered by basic insurance)

- improving the current system of direct payment by beneficiaries (supplementary charges and administrative fees)

- reducing the income share of primary health care doctors which mainly originates from a payment mechanism based on the relationship between prices and services and payment on the basis of individual cases

- hospital categorisation and accreditation, making hospitals specialise in individual fields so as to improve the quality of services and, eventually, reduce costs as well

- basing the payment of hospital charges on the DTG mechanism (diagnostic-therapeutic groups)

- harmonising the purchase and use of diagnostic equipment with hospital categorisation and accreditation

- introducing smart cards in order to monitor financial and natural indicators per patient and doctor

- making a positive drug list with reference price lists.

The health care system in Croatia is a social insurance system. It is largely funded from public revenues via employer contributions and funds from the National Budget; therefore, the Croatian health care system can be said to have characteristics of the Bismarckian and Beverage systems. The government collects contributions for health insurance and directs them to the National Treasury. When adopting the national budget, the Croatian parliament, upon the proposal of the Ministry of Health and Social Welfare, decides on the amount allocated in the annual national budget to health care. The Croatian Health Insurance Institute independently collects funds from additional health insurance for insured people holding an additional health insurance policy with the Croatian Health Insurance Institute.

Employers' contributions

The health protection system is mostly funded by social insurance contributions, which defines Croatia as one of the countries with a Bismarckian health insurance model.

The contribution rate is calculated in relationship to wages and amounts to $15 \%$. Following 2003, only employers are obliged to pay contributions, i.e. the costs of funding compulsory health insurance are no longer divided between employers and employees, which was the case between 2000 and 2002 when the employer's contribution was $7 \%$ of wages and the employee's $9 \%$. After 2002, contributions have not been independently collected by the Croatian Health Insurance Institute, implying that the Institute has lost its autonomy within the social insurance system.

Compulsory contribution rates are often related to the flexibility of the labour market and labour costs in Croatia. Thus, there are those who believe that health care 
contributions actually increase employers' labour costs, with regard to the $15 \%$ health insurance contribution rate, and that this encourages employers to hire illegal labour. There are also initiatives to relieve employers of a part of health insurance costs in order to reduce labour costs so as to stimulate employers to create new jobs. Certainly, there is no need to dwell on the consequences this might have for the funding and sustainability of the health care system, but also in terms of limiting the right of citizens to health care services.

Compulsory health insurance contributions must be paid by all employees, selfemployed people and farmers. Health insurance contributions for certain vulnerable categories of citizens are paid out of the national budget and the budgets of local administrations and self-governance units. Such vulnerable groups include the unemployed, people with disabilities, those under 18, students, war veterans and the military.

Around $80 \%$ of health care costs in Croatia are funded out of compulsory health insurance contributions based on wages. The remaining $20 \%$ is funded by transfers from the budgets of central government and local self-governance units, i.e. from other tax revenues, participation in additional and voluntary health insurance, loans raised by the Croatian Health Insurance Institute and other sources. National budgetary funds are used, for instance, for funding additional maternity leave and additional health care for people over 65 and children under 18, emergency medical services on national roads, health care education, etc. National budgetary funds are also used for funding the costs of public health and environmental protection, as well as for capital investment. Similarly, the same budget is the source of funds for the local self-governance units which are used (on the approval of the Ministry of Health and Social Welfare) to invest in buildings, equipment, etc.

Health care compensation in primary health care is related to a poll tax and, in 2004, a payment mechanism related to individual services was introduced, first for preventive programmes and then also for curative treatments.

A payment mechanism related to individual therapeutic procedures (the so-called diagnostic therapy group system) was introduced in 2005. Hospitals are funded from monthly budgets in respect of which they have to submit bills for their services. Together with defining the total budget, hospital health care is also funded through payment mechanisms related to services and therapeutic procedures.

The need to reform the Croatian public health system created the need to separate health insurance into compulsory and voluntary insurance. Compulsory health insurance remains social in nature and is based on solidarity while voluntary insurance largely encroaches on the field of the free market system.

The new Compulsory Health Insurance Act of July 2006 (Official Gazette No. 85/ 06) defines health insurance as compulsory (within the competence of the Croatian Health Insurance Institute) and voluntary (defined by separate regulations). This law defines the individual categories of people encompassed by health insurance which includes people paying health insurance contributions on the basis of their employment as well as that of other people such as family members, students, people registered with unemployment bureaus, etc. In fact, compulsory insurance includes almost the entire population, illustrated by $97 \%$ of the population being covered by insurance. Those who are not covered are usually people who have not met the Insti- 
tute's registration deadlines, which also includes people working abroad who have not regulated their status in Croatia.

The Voluntary Health Insurance Act (Official Gazette No. 85/06) defines voluntary health insurance as:

- additional

- supplementary

- private.

\section{Additional health insurance}

Additional health insurance provides coverage of a part of the costs, up to the full health care price arising from compulsory health insurance (supplementary charge). Additional health insurance is within the competence of the Croatian Health Insurance Institute and those insurance companies registered for insurance activities in the Republic of Croatia. Together with additional insurance, such companies can also offer supplemental and private health insurance which provide a wider range of rights, a higher standard of services and certain rights not encompassed by compulsory health insurance. After 2004, this type of insurance has also covered the participation share.

With this type of insurance, the policy holder is the insured party, a legal or natural person, a state authority or other body concluding the contract on behalf of the policy holder on additional health insurance and assuming the liability to pay the insurance premium.

The insured party can only be a natural person officially holding the status of an insured person within compulsory health insurance. The duration of the contract can be no less than one year.

\section{Supplementary health insurance}

Supplementary health insurance, as a new type of voluntary insurance, ensures a higher standard of health protection as well as a wider range of rights in comparison with that of compulsory health insurance. Therefore, if a patient requests a separate room during hospital treatment, the costs of this are covered from their supplementary health insurance policy.

This is established by a contract on supplementary health insurance between the policy holder and the insurer, where the policy holder can be an insured person, a legal or natural person, a state authority or other body concluding the contract on behalf of the policy holder on supplementary health insurance and assuming the liability to pay the insurance premium.

The insured person can only be a natural person officially holding the status of an insured person within compulsory health insurance. The duration of the contract can be no less than one year.

\section{Private health insurance}

This provides health protection to natural persons staying in the Republic of Croatia who are not obliged to be insured under the Compulsory Health Insurance Act and the Health Care for Aliens in Croatia Act.

It is established by a contract on supplementary health insurance between the policy holder and the insurer, where the policy holder can be an insured person, a legal or 
natural person concluding the contract on behalf of the policy holder and assuming the liability to pay the insurance premium.

The contract on private health insurance defines the health care institutions, trading companies involved in health care and private health professionals offering rights related to private health insurance.

\section{Participation}

One result of the past reforms has been a continuing tendency to increase the share of citizens' private resources in the funding of health care services. This has been the aim of all governments, i.e. the pursuit of a policy of 'privatisation and economic restructuring' of the health care system. In order to increase control over health care expenditure, governments have tried to prevent expenditure through measures which primarily reduce supply or measures aimed both at reducing demand for health care services and raising the financial awareness of insured parties. This has given rise to ideas on a sharing of health care costs through participation, on the list of drugs charged to the account of basic health insurance, on developing a private sector in health care, etc.

Within the basic insurance system today, patients cover participation to an amount varying between $15 \%$ and $75 \%$, and up to $100 \%$ for medicines. In most cases, the Croatian Health Insurance Institute does not cover the costs of procedures carried out in private health care institutions, such as specialist and dental practices. Health authorities have stressed the importance of participation as an instrument for increasing the share of private funds in health care. However, participation has only slightly relieved the Institute's budget since most insured persons are exempt from participation. Still, in the case of certain low-income categories, such as pensioners, people with disabilities and patients with chronic diseases, health care costs considerably burden their budgets. Costs of participation can be reduced through additional health insurance, but its introduction can be said not to have relieved the Institute's budget significantly.

\section{External funding sources}

After 1993, the World Bank has offered its financial and expert assistance to Croatia by means of a number of loans, and has also shaped the health care policy and the entire health care system in Croatia, offering its expert and analytic services to the country.

It should also be taken into account that local administration and local self-governance units participate in the funding of health care. According to World Bank data from 2002, local authorities spent around $3 \%$ of their revenues on health care, in contrast to which they spent around $20 \%$ on education, for instance.

Unfortunately, there are no data on the private funds which citizens spend on health care, but the government estimates that they amount to $2 \%$ of GDP. However, according to data offered by the World Health Organisation, the share of private resources in 2004 amounted to 19\% of GDP. Private resources include participation, additional health insurance and voluntary health insurance. The financial goals of the Strategy have gradually been implemented so that the total health expenditure of $9 \%$ of GDP in 2000 fell to $7.7 \%$ in 2004, while the share of private resources in GDP has grown at the same time. 
Health care system employees

In late 2006, the health care system of the Republic of Croatia had 68539 permanently employed staff (2005 - 67 716). Out of this, health professionals and staff members accounted for 50687 employees, administrative staff for 4949 and technical staff for 12903 . In the composition of permanently-employed staff, health professionals with secondary school qualifications accounted for $37.8 \%$; administrative and technical staff $26.0 \%$ (2005 - 26.5\%); doctors $16.4 \%$; health professionals with a two-year degree $9.7 \%$; dentists $4.6 \%$; pharmacists $3.7 \%$; health care staff members with university qualifications (psychologists, speech pathologists, social workers, speech therapists and others) $1.1 \%$; and semi-skilled health workers $0.6 \%$.

The system also included 7913 (2005 - 7921) health professionals and staff members employed for a fixed-term period; on 31 December 2006 there were 58600 health professionals and staff members employed either permanently or temporarily.

Privately-owned facilities - polyclinics, specialised hospitals, sanatoria, practices, occupational medicine institutions and trading companies involved in health care or private health care - included 1130 permanently employed doctors (10\% of the total). In addition to staff with permanent positions, in late 2006 there were also 899 doctors employed temporarily, making a total of 12,149 doctors.

There were 32555 health professionals with secondary school qualifications and two-year degrees, out of which nurses accounted for 72\% (23 355) while the remaining staff were mostly composed of health engineers and technicians.

In 2006, there were 2.1 nurses per one permanently employed doctor.

In 2002, Croatia had around 2.38 doctors per 1000 citizens which was lower than in other EU member states (e.g. the Czech Republic had 3.87 and Germany 3.33) except for Slovenia (which had 2.27). The major shortage is related to nurses - there are almost $60 \%$ less nurses than specified by EU standards.

The wages of health care employees are regulated by the basic collective agreement for public service employees, as well as by the sectoral collective agreement for health care and health insurance. The rights of employees within private practice are regulated by the collective agreement for private practice health care in Croatia. Table 1 shows the average monthly wage in health care and social welfare:

Table 1 - Average monthly net earnings per person in paid employment in legal entities (in kuna), according to NKD (2002)

\begin{tabular}{|l|c|c|c|c|c|c|c|c|c|}
\hline & Total & $\begin{array}{c}\text { University } \\
\text { degree }\end{array}$ & $\begin{array}{c}\text { Non-university } \\
\text { college degree }\end{array}$ & $\begin{array}{c}\text { Secondary } \\
\text { education }\end{array}$ & $\begin{array}{c}\text { Basic } \\
\text { education }\end{array}$ & $\begin{array}{c}\text { Highly- } \\
\text { skilled }\end{array}$ & Skilled & $\begin{array}{c}\text { Semi- } \\
\text { skilled }\end{array}$ & $\begin{array}{c}\text { Un- } \\
\text { skilled }\end{array}$ \\
\hline $\begin{array}{l}85 \text { Health } \\
\text { and social } \\
\text { work }\end{array}$ & 5088 & 8474 & 5352 & 4443 & 2775 & 4443 & 3814 & 2495 & 2587 \\
\hline
\end{tabular}

\section{Rights arising from health insurance}

The rights arising from health insurance include the following:

- the right to health care

- the right to financial compensation.

The right to health care includes the right to:

1. primary health care

2. specialist and advisory health care 
3. hospital health care

4. the right to use medicines defined by the Institute's basic and additional drug lists

5. the right to dental and prosthetic care and prosthetic dentistry substitutes

6. the right to orthopaedic and other aids

7. the right to health care abroad.

The law defines the parts of health care that are fully covered and those that are partially covered, with the coverage being $85 \%, 75 \%, 70 \%$ or $50 \%$ of the service price. The last category includes, for instance, dental health care in mobile and fixed adult prosthetics. Compulsory insurance fully covers medicines from the basic drug list, while the additional list also includes the amount of the supplementary charge for certain medicines. The following categories are exempt from health care co-funding:

- children under 18

- people with disabilities and other people requiring the help of another person for most or all vital activities, in accordance with separate regulations

- people with no less than $80 \%$ physical disability, in accordance with the pensions insurance legislation or the Law on the Rights of Croatian War Veterans and Their Families, or other separate laws; people with physical disabilities

- voluntary blood donors with over 35 donations (men) or 25 (women)

- people whose income per family member in one year does not exceed a specified amount (i.e. if the total monthly income per family member does not exceed $45.59 \%$ of the budgetary basis; for single pensioners, $58.31 \%$ ).

The last category caught the greatest public attention when the Law was being adopted, mostly with regard to whether the new provisions on co-funding would have a negative effect on the availability of health care to low-income citizens. It is important to note that this implies total income, although it is still not clear what procedure would be used to identify this income. Future health policy will certainly have to take into consideration the effects of co-funding not only on citizens who should be exempt from it on this basis but also on those citizens who will not be exempt and whose income is barely able to cover large sums. This law also introduced administrative fees to an amount of not less than five kunas and not more than 30 kunas per month. The fees are paid by all those using health care except for children under 18 and people with no less than $80 \%$ disability. In accordance with its 2007 election promise, the Croatian government amended the Law to lift administrative fees in 2008.

The right to financial compensation includes:

- compensation for wages during temporary incapacity or inability to work (sick leave), or financial compensation on the basis of an inability to perform tasks being the basis for other income

- compensation for travel expenses related to the use of health care within compulsory health insurance.

\section{Health care availability to Croatian citizens}

All reform steps are directed towards the commercialisation of health care services. Health care is increasingly becoming a commodity and a commodity has its price; some can afford it and some (i.e. most) cannot. This has the following consequence: 
the availability of timely and high-quality health care depends on the financial standing of an individual. This will result in separating citizens into those who have access to an increasingly-reduced number of health care rights and those who have more rights since they can afford them. Moreover, certain legislative solutions are putting patients in an increasingly unfavourable position. The announced increase in participation relating to the funding of the provision of health care services can mean 'bankruptcy' or the unavailability of treatment for seriously-ill or chronic patients. The explanation of high rates of participation is that they stimulate a more responsible behaviour towards one's own health and reduce health care expenditure. Research, however, indicates that they have this effect only on the low-income population who neglect their treatment and timely visits to physicians, and that they have no such effect on that part of the population of better financial standing.

In this context, it is also necessary to mention the Protection of Patients' Rights Act (Official Gazette No. 169/04) which, for the first time, regulates the rights of patients. This is certainly a huge and important step for the Croatian health care system, despite strong criticism. It will certainly take a lot more time for certain rights to be guaranteed by law and respected in practice.

Furthermore, the availability of health care to citizens is also influenced by primary health care doctors being paid on the principle of a 'poll tax' - a lump sum they receive from the Croatian Health Insurance Institute for each insured person. This payment system was introduced in the early 1990s. It was not taken into consideration, however, that such lump sums for each registered patient would stimulate doctors to have as many patients as possible. Thus, it can happen that doctors have too many patients on their lists at a particular point of time. This reduces the number and quality of services provided - doctors do not have enough time to devote their attention to each individual patient but try to perform check-ups as quickly as possible to allow them to see as many patients as possible. An additional factor in the transfer of services from primary health care to higher health care levels is that, under the "poll tax' system, general practitioners do not have capacities to equip their practices adequately and are often forced to refer patients to polyclinics or hospitals, thus increasing health care expenditure.

Moreover, the engagement of primary health care physicians in private practice is inadmissible, according to trade unions, as it directs patients towards private practice under the pretext that services (diagnostic procedures, treatment of patients, medical services) are provided faster than in the public health system. Such a legal engagement of hospital physicians from the public health system in private practice is, we believe, conducive to abuse, to the detriment of public health patients and to increasing social inequality in the public health care system. It adds to waiting lists in the public health system; reduces the attention that doctors pay to the needs of patients in the public health system, while their efficiency during regular working hours may easily become questionable; and contributes to an indirect transfer of public health care resources to private pockets (when professionals who offer public health care use public institutions for offering specialist services to their private patients, the public sector is subsidising unofficial private practice). 


\section{Conclusion}

The Croatian health care system has been in a state of 'permanent' transition for almost two decades.

If we were to summarise the achievements of the health care reforms, the result would be the following: citizens are paying more and more money for increasingly inefficient and low-quality health protection. The inability of the government to structure the public health care system in accordance with the Constitution of the Republic of Croatia is something that we are all paying for, while the poor, sick and infirm are paying disproportionately more. There is certainly no need to emphasise that there has been no social consensus on the direction and concept of health care reform and neither is there a chance for this to be reached. Meaningful social dialogue about it is also lacking - interest lobbies (from financial to medical ones) seem to have the crucial influence on the concept of health care reforms.

The Croatian health care system is designed so as to make the specific rights of insured people dependent on (increasingly) numerous laws governing health care and countless by-laws (rules of procedure, decisions) which govern the specific implementation of their rights. Rules of procedure and decisions often change, so that health care beneficiaries are exposed to legal insecurity in exercising their constitutional right to health.

Until recently, Croatia used to be one of the few countries with a strong public health care tradition. The overall results of the so-called reforms and measures in health care can be boiled down to the following:

- primary health care is fragmented and reduced to a number of small, individual units where nurses spend a considerable amount of time on administrative tasks and physicians are often reduced to 'dispatchers'

- the main obligation of these small units is to pay the rent regularly to community health centres and to stay within the imposed expenditure limit

- physicians are often deprived of the possibility of using basic diagnostic infrastructure (community health centres have rather poor medical and diagnostic equipment)

- specialist health care has almost assumed the role of primary health care while waiting lists for check-ups, medical and hospital treatment are becoming longer

- bribery and corruption thrive within the system - however, they are impossible to prove and are, therefore, non-existent

- hospital limits are mainly unrealistic and not compatible with costs

- more and more funds are spent on wages to the detriment of services

- changes introduced into the accounting system do not register depreciation costs, thus artificially reducing health care costs, resulting in outdated equipment, insufficient investment maintenance and the deterioration of capital assets.

Trade unions support a strong and efficient public health care system based on solidarity, with private health insurance operating around the margins as a regulator of health issues (providing some additional options for some less relevant health care services). Namely, private insurance companies focus on financially interesting services, not those which are relevant in terms of health care, and evidently increase the costs of the health care system as a whole. The Croatian Health Insurance Institute should be an independent institution (similarly to the role of the Croatian National 
Bank in comparison with other banks), while the Institute's resources should be separated from the National Treasury.

In all health care institutions, management and medical functions should be clearly distinguished and treated as equal.

This leads to the conclusion that the problems faced by Croatian health care are neither new nor unique. Many new and acceptable solutions, and many of the mistakes to be avoided, can be encompassed within a debate including all the interested stakeholders on the creation, implementation and supervision of public health policy. The effects of the health care reforms are felt by the entire population as soon as the reforms are carried out. This means that health care reform must operate in the interest of the entire society, not just the political elite.

\section{References}

'Nacionalna strategija razvitka zdravstva' (2006-2011) [National Strategy for Health Development (2006-2011)] Official Gazette No. 72/2006.

The Joint Social Inclusion Memorandum signed by the Government of the Republic of Croatia and the European Commission on 5 March 2007.

Compulsory Health Insurance Act (Official Gazette Nos. 85/06, 105/06, 118/06, 77/ 07, 111/07 and 35/08).

Voluntary Health Insurance Act (Official Gazette No. 85/06)

Health Care Act (Official Gazette Nos. 121/03, 48/05 and 85/06)

Health Care Act (Official Gazette Nos. 75/93, 55/96, 1/97 - revised text, 111/97, 95/ 00 and 129/00)

Health Care for Aliens in the Republic of Croatia Act (Official Gazette No. 114/97).

Occupational Health Care Insurance Act (Official Gazette No. 85/06).

Law on Maternity Leave of Self-Employed and Unemployed Mothers (Official Gazette Nos. 24/96, 109/97, 82/01 and 30/04).

Medicines and Medical Products Act (Official Gazette Nos. 121/03 and 177/04).

Compulsory Insurance Contributions Act (Official Gazette Nos. 147/02, 175/03 and 177/04).

Rule Book on the Rights, Requirements and Manner of Realising Rights from Compulsory Health Insurance (Official Gazette Nos. 121/06, 136/06, 56/07, 80/07, 96/ 07 and 45/08).

Health Insurance Act (Official Gazette Nos. 94/01, 88/02, 149/02, 117/03, 30/04, 177/ 04 and 90/05).

Exemption from Payment of One Part of Health Care Costs (Official Gazette Nos. 32/ 02 and 30/04).

Report on Financial Operations of the Croatian Health Insurance Institute for the period January-December 2007.

European Observatory on Health Systems and Policies: Health Systems in Transition: Croatia - Health System Review. 
Zrinščak, Siniša (2007) 'Zdravstvena politika Hrvatske. U vrtlogu reformi i suvremenih društvenih izazova' Revija za socijalnu politiku 14(2).

Dubravko, Mihaljek: Zdravtevan politika i reforma u Hrvatskoj: Kako vidjelti šumu od drveća.

European Commission (2005) Croatia: Progress Report SEC(2005)1424, Brussels, 9 November.

National Institute for Statistics (2007) Statitsički ljetopis.

Croatian Public Health Institute (2006) Hrvatski zdravstveno-statistički ljetopis. 